INTERNATIONAL JOURNAL OF RESEARCHES IN BIOSCIENCES, AGRICULTURE AND TECHNOLOGY

C VISHWASHANTI MULTIPURPOSE SOCIETY (Global Peace Multipurpose Society) R. No. MH-659/13(N)

www.vmsindia.org

\title{
ELECTIRCAL CONDUCTANCE PROPERTIES OF TERPOLYMER RESIN DERIVED FROM O-AMINO PHENOL DITHIOOXAMIDE AND FORMALDEHYDE
}

Sharayu S. Katkamwar

Arts, Commerce and Science College, Tukum, Chandrapur-442401, India. katkamwarsharayu@gmail.com

\section{Abstract:}

Terpolymer resins o-APDF have been prepared by the condensation and dithio oxamide with formaldehyde in the presence of acid catalyst and using varied molar ration of reacting monomers. The electrical conductivity terpolymer were measured over a wide range of temperature in their pellets from. From the electrical conductivity of this polymer activation energy of electrical conduction have been evaluated and values lies in the range. $1.18 \mathrm{x}$ $10^{-4}$ to $6.88 \times 10^{-4} \mathrm{ev}$. The terpolymer at room temperature have an electric conductivity in the range $1.69 \times 10^{-7}$ to $1.17 \times 10^{-8}$ Siemen.

Keywords : Terpolymer, Conductance, Temperature, energy

\section{Introduction:}

The organic polymers have attracted the attention of many research workers. The wide range of useful properties available in commercial polymers stimulated many investigators to perceive the great potential of a semiconducting material. However there were some disadvantages which might decrease the carrier mobilities of the organic semiconductors such as the forces between the adjacent molecules are relatively weak as organic compounds form molecular crystals. Due to little electronic coupling that exists between the adjacent molecules it becomes difficult for the electrons to jump from one molecule to the other. As a consequence of the disordered structure which is due to amorphous nature, the electrons get scattered while traveling through the materials, when they try to flow through it and hence lowers the conductivity. New approaches have been implemented by various research groups in order to overcome the fabrication difficulty. Such approaches stem from synthetic chemistry methods [11] with the incorporation of side groups that make the polymer soluble. New techniques for growing films electrochemically [2] and to improve the solubility in standard organic solvents [3] have been going to be developed. These major efforts have not paid off which is demonstrated producing large number of conducting polymer world wide, some of them commercially available [4]. Efficient processing of conjugated polymer materials into useful forms and the fabrications of electronic and optoelectronic devices require input from engineering i.e. material science (more specifically, polymer science) and device physics. Because of the progress toward higher purity, processible semiconducting polymers are now available for use in 'plastic electronic device'. Plastic electronics devices include diodes, photodiodes, photovoltaic cells, sensors, light emitting diodes, lasers, field effect transistors and all polymer integrated circuits and the list is growing.

\section{Material and Methods: Experimental:}

A mixture of ortho amino phenol (1.09gm, $0.1 \mathrm{~mol})$, and dithiooxamide (1.20 gm, $0.1 \mathrm{~mol})$ and formaldehyde $(7.50 \mathrm{ml}, 0.2 \mathrm{~mol})$ in molar ratio of $1: 1: 2$ in the presence of $2 \mathrm{M}(200 \mathrm{ml}) \mathrm{HCl}$ as a catalyst has been prepared in round bottom flask. The resultant mixture was refluxed over an oil bath for heating at $122^{\circ} \mathrm{C} \pm 2{ }^{\circ} \mathrm{C}$ for $5 \mathrm{hrs}$ with occasional shaking to ensure thorough mixing. The temperature of oil bath was controlled electrically with the help of dimmerstat. The resinous sticky brown solid mass obtained was immediately removed from the flash as soon as the reaction period was over and then its purified. Excellent yield of terpolymer resin can be obtained by this reaction.

\section{Measurement Of Resistivity:}

The resistance of samples were measured by using two prob method. The electrical circuit for the DC resistance measurement consists of electronic regulated power supply and LCR-Q tester-model 4910 with a least count of 1 uv and input-impedance of $10 \mathrm{moh}$. Connection wires from the furnace were. connected to the terminals of the instrument. In this way corresponding resistance of the pellet was measured by keeping the pellet in sample holder. Resistivity $(\sigma)$ was then calculated using the relation. $\quad \sigma=\mathrm{R} \times \mathrm{A} / 1$ where,

$\begin{array}{lll}\mathrm{R} & = & \text { Resistance of the pellet } \\ \mathrm{A} & = & \text { Surface area of the pellet } \\ 1 & = & \text { Thickness of the pellet } \\ \sigma & = & \text { Resistivity. }\end{array}$


The conductivity measurements were made over a wide range of temperatures. The electrical conductivity $(\sigma)$ varies exponentially with the absolute temperature according to well known relationship,

$\sigma=\sigma o \exp (-\mathrm{Ea} / \mathrm{kT})$

where,

$\sigma=$ Electrical conductivity at temperature $\mathrm{T}$.

$\sigma_{o}=$ Electrical conductivity at temperature $\mathrm{T} \rightarrow \infty$

$\mathrm{Ea}=$ Activation energy of electrical conduction.

$\mathrm{k}=$ Boltzmann Constant $\left(1.3817 \times 10^{-23} \mathrm{~J}\right.$ molecule ${ }^{-1}$ K.-1).

$\mathrm{T}=$ Absolute temperature.

This relation has been modified as,

$$
\log \sigma=\log \sigma_{0}+\frac{-\mathrm{Ea}}{2.303 \times \mathrm{kx} \mathrm{T}}
$$

According to this relation, a plot of log $\sigma \mathrm{Vs}$ $1 / \mathrm{T}$ would be linear with negative slope. Such plots were made on the basis of each set of data. From the slopes of the plots, the activation energy (Ea) of electrical conduction was calculated.

\section{Result and Discussion:}

The DC resistivity of the o-APDF terpolymer resins was measured in the temperature range $303-433 \mathrm{~K}$ by applying a constant voltage (50 volts) across the pellet. The experimental results of electrical conductivity of o-APDF terpolymers are incorporated in Table1. The temperature dependence of the electrical conductivity of these terpolymers is shown in Fig.1. The following conclusions have been drawn from the results of electrical conductivity data.

1. The electrical conductivity of o-APDF terpolymer resins at room temperature lies in the range of $1.69 \times 10^{-7}$ to $1.17 \times 10^{-8}$ Siemens.

2. The plots of $\log \sigma$ versus $1 / \mathrm{T}$ are found to be linear in the temperature range under study, which indicate that the Wilson's exponential law $\sigma=\sigma_{o} \exp (\Delta \mathrm{E} / \mathrm{kT})$ is obeyed.
3. Electrical conductivity of each of these terpolymer resins increases with rise in temperature. Hence, these terpolymers may be ranked as semiconductors.

4. The energy of activation (Ea) of electrical conduction calculated from the slopes of the plots is evident, to be in the range of $1.18 \times 10^{-4}$ to $6.88 \times 10^{-4} \mathrm{ev}$. These are collaborated by the findings of earlier workers $[1,3,5,6,10]$.

5. The energy of activation is found to be in following order, o-APDF-I > o-APDF-II > o-APDFIII > o-APDF-IV.

The electrical conduction of polymeric material depends upon uncalculated parameters[7]such as porosity, pressure, method of preparation, atmosphere etc., but activation energy (Ea) is not affected by these parameters and therefore it is fairly reproducible[ 8,9$]$. The magnitude of activation energy depends on the number of $\pi$ - electrons present in the semiconducting material. More the number of $\pi$ - bonds -lower is the magnitude of activation energy (Ea) and vice-versa Generally polymers containing aromatic nuclei in the backbone exhibit a lower activation energy than those with aliphatic system. Thus, the low magnitude of activation energy may be due to the presence of large number of $\pi$ electrons in the polymer chain. Moreover, the increasing order of electrical conductivity and decreasing order of activation energy of electrical conduction as shown above may be due to introduction of more and more aromatic skeleton (and therefore more and more $\pi$ electrons) in the structure of repeat unit of terpolymers, which is in good agreement with the most probable structure proposed for the newly prepared 8-HQDF, P-CDF, p-APDF and oAPDF terpolymer resins under present investigation.

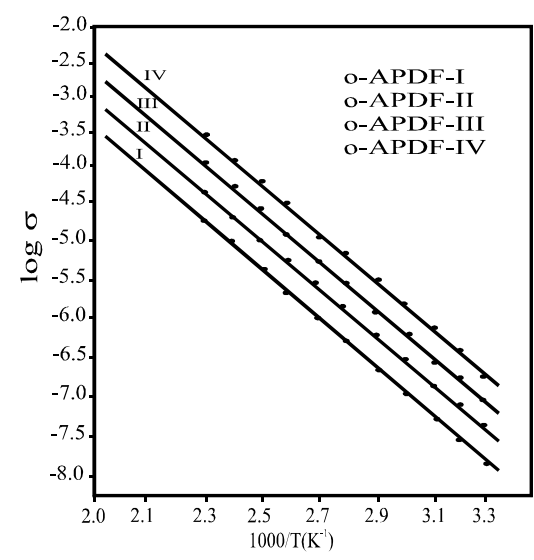

Fig. 1 - Electrical Conductivity Plots of o-APDF Terpolymer Resins 
Table 1 - Electrical Conductivity Data of o-APDF Terpolymer Resins

\begin{tabular}{|l|l|l|l|l|}
\hline \multirow{2}{*}{ Terpolymers } & \multicolumn{2}{|l|}{ Electrical Conductivity } & \multicolumn{1}{c|}{$\begin{array}{l}\square \\
\text { (K) }\end{array}$} & $(\mathrm{ev})$ \\
\cline { 2 - 4 } & $303 \mathrm{~K}$ & $433 \mathrm{~K}$ & $303-433$ & $6.88 \times 10^{-4}$ \\
\hline o-APDF -I & $1.17 \times 10^{-8}$ & $1.60 \times 10^{-5}$ & $303-433$ & $1.09 \times 10^{-4}$ \\
\hline o-APDF -II & $1.15 \times 10^{-7}$ & $2.04 \times 10^{-8}$ & $303-433$ & $1.14 \times 10^{-4}$ \\
\hline o-APDF -III & $1.27 \times 10^{-7}$ & $2.00 \times 10^{-8}$ & $3.03-433$ & $1.18 \times 10^{-4}$ \\
\hline o-APDF -IV & $1.69 \times 10^{-7}$ & $7.57 \times 10^{-5}$ & $303-43$ \\
\hline
\end{tabular}

\section{References:}

Aswar A.S., Mahale R.G., Kakde P.R., Bhadange S.G., J. Ind. Chem., Soc., 25, 395-397 (1998).

Athawale A.A., Patil S.F., Deore B., Polymer International, 45, 195 (1998).

Azaroff L.V., "Introduction to Solids", McGraw Hill INC, New York (1960).

Cao Y., Smith P., Heeger P., Synth. Mat., 57, 3514 (1993).

Dunlop W.V., "An introduction to semiconductor", Wiley, New York, 189 (1957).
Cao Y., Treacy G.M., Smith P., Heeger A. J., Synth. Mat., 55, 3526 (1993).

Hiberer A., Brouwer H.J., VandorScheer B.J., Wildman J., Macromolecules, 28, $4525-4529$ (1995).

Pal T.K., Kharat R.B., J. Indian Chem. Soc, 27 A, 85 (1988).

Patel M.M., Manavalan R., J. Ind. Chem., Soc., LXI, 490 (1984).

Rahangdale P.K., Ph.D, Thesis, RTM Nagpur University, Nagpur (1995).

Robitaile L., Bergeron J.Y., D. Aprano G., Lecterc M., Thin Solid Films, 244, 728 (1994). 